\title{
TWO-STEP CROSSLINKING OF PVP/GEL NANOFIBERS
}

\section{DOI: 10.35530/TT.2021.25}

\author{
H.K. Güler*, F.C. Çallığlu
}

Textile Engineering Department, Engineering Faculty, Süleyman Demirel University, Turkey (E-mail: hulyakesici@sdu.edu.tr, fundacengiz@sdu.edu.tr)

\begin{abstract}
In this study, it was achieved that crosslinking of PVP/GEL nanofibers with two-steps. Crosslinking is a process highly important for water-soluble polymers in terms of application areas and mechanical properties. Firstly, crosslinking of PVP polymers experimental studies were carried out via heat treatment at different temperatures and times. Then, GEL polymers were crosslinked with GTA vapour at different times. Morphological analysis was carried out via SEM images and chemical characteristics were determined via FT-IR analysis. Moreover, after the crosslinking process, SD and WL values were calculated. All results showed that before crosslinking of SEM images, nanofibers were smooth, fine and without beads. The average fiber diameter is $196 \mathrm{~nm}$ and the fiber diameter distribution is quite uniform. After crosslinking of SEM images, it is expected that all nanowebs will turn from fibrous surfaces to membranous. Generally, SD and WL values decrease with crosslinking time increase. According to all of the SEM images, SD and WL values, optimum conditions were determined for PVP as 4 hours at $180^{\circ} \mathrm{C}$ and for GEL as 24 hours. Lastly, the presence of PVP and GEL polymers in the nanofiber structure was verified chemically with FT-IR analysis.
\end{abstract}

Keywords: crosslinking, electrospinning, gelatin, nanofiber, poly(vinyl pyrrolidone)

\section{INTRODUCTION}

Poly (vinyl pyrrolidone) (PVP) is a water soluble, biocompatible, nontoxic, synthetic and hydrophilic polymer. Similarly, gelatin (GEL) is a natural, protein-based, non-immunogenic, biodegradable, and biocompatible polymer. All of these features are critical in biomedical and cosmetic applications such as wound dressing, tissue engineering, drug delivery and controlled release systems [1-3].

Electrospun nanofibers have unique properties than conventional fibers, such as small fiber diameter (nm), high porosity, small and open pore structure, large specific surface area $\left(\mathrm{m}^{2} / \mathrm{g}\right)$, and high loading capacity. However, if a water-soluble polymer is used during the production of nanofibers, it may be necessary to make them water resistant depending on the application areas. Crosslinking is a method used to make nanofibers water resistant. After the crosslinking process, the polymers become stable in water and aqueous environments. When the literature is analyzed, generally, the PVP polymer is crosslinked using heat treatment or UV light. It is seen in the literature that PVP based nanofibers are crosslinked using heat with different temperature ranges from $140^{\circ} \mathrm{C}$ to $210^{\circ} \mathrm{C}$ and different times, such as 14 min., 30 min., 1 hour, 2 hours, 3 hours etc. [4-5]. GEL nanofibers are mostly crosslinked chemically using glutaraldehyde (GTA). Here, GTA was either added directly into the polymer solution or the nanofibrous surface was exposed to GTA vapors for different times ( 1 hour, 3 hours, 6 hours, 12 hours, 24 hours, and 48 hours etc.) at room temperature. Moreover, some 
researchers immersed the gelatin based nanoweb into the GTA solutions for crosslinking [6-7].

In this study, it was aimed at crosslinking and characterizing PVP/GEL nanofibers. Crosslinking of two different water-soluble polymers in a single nanoweb is very limited in the literature. Moreover, crosslinking of nanofibers consisting of both PVP and GEL polymers has not been reported in the literature yet.

\section{MATERIALS AND METHODS}

\subsection{Materials}

In this study, PVP (360.000 $\mathrm{g} \mathrm{mol}^{-1}$ ) was used as a polymer and GEL from porcine skin (gel strength 300, Type A) was used as a copolymer. Ultra-pure water (UPW) and acetic acid (AA) were used as the solvents. Glutaraldehyde (GTA) was used as a crosslinker. PVP, GEL, GTA, and AA were purchased from Sigma-Aldrich Corporation (St. Louis, MO, USA) and UPW was obtained from a Millipore Milli-Q System with a conductivity of $18.0 \mathrm{M} \Omega . \mathrm{cm}$. The polymer concentrations were kept constant for PVP and GEL at $12 \mathrm{wt} \%$ and $0.72 \%$ wt, respectively.

\subsection{Methods}

Nanofibers were produced using an electrospinning method. During the electrospinning process, $26.4 \mathrm{kV}$ voltage, $0.3 \mathrm{~mL} / \mathrm{h}$ feed rate, $17.0 \mathrm{~cm}$ distance between electrodes, $33 \pm 2 \%$ humidity, and $23.5 \pm 1^{\circ} \mathrm{C}$ temperature were applied. The optimum process parameters were determined from our preliminary studies.

The crosslinking process was carried out in two steps. Firstly, optimum conditions in terms of temperature and time were determined by performing crosslinking of PVP polymer in a vacuum oven at different temperatures $\left(150^{\circ} \mathrm{C}, 180^{\circ} \mathrm{C}\right.$, and $\left.200^{\circ} \mathrm{C}\right)$ and at different times (1, 2, 3, 4, and 5 hours). In the second step, the GEL polymer was crosslinked with GTA vapors. For this purpose, optimization studies were carried out by placing the nanofibers on the perforated porcelain tray of a $25 \mathrm{~cm}$ diameter desiccator containing $10 \mathrm{~mL}$ of GTA and keeping them at room temperature $\left(24^{\circ} \mathrm{C}\right)$ for $3,6,12,24$, and 48 hours.

After crosslinking optimization studies, nanowebs were investigated morphologically by SEM images with 5.000x magnification. Then, the crosslinked nanofibers were soaked in distilled water at room temperature $\left(24^{\circ} \mathrm{C}\right)$ for 24 hours and the weight loss (WL) and swelling degrees (SD) were calculated. The samples' water resistance was tested, and the weight loss ratio of the samples was determined using Eq. 1, where $\mathrm{W}_{0}$ represents the initial weight of the samples and $\mathrm{W}_{1}$ represents the dry weight of the samples after water treatment. The swelling ratio was evaluated in the same method as the weight loss tests, using Eq 2, where $\mathrm{W}_{2}$ is the weight of the swelled samples and $\mathrm{W}_{1}$ is the weight of the dry samples after water treatment was applied.

$$
\begin{aligned}
& W L(\%)=\frac{W_{0}-W_{1}}{W_{0}} \\
& S D(\%)=\frac{W_{2}-W_{1}}{W_{1}}
\end{aligned}
$$

In addition, a Fouirer Transform Infrared Spectrophotometer (FT-IR) was used to chemically determine the presence of polymers (PVP and GEL) in the structure of nanofibers. The device used was a Perkin Elmer Spectrum BX model device with a $2 \mathrm{~cm}^{-1}$ 
resolution between 400 and $4000 \mathrm{~cm}^{-1}$ wavelength and was used in accordance with the $\mathrm{KBr}$ disc technique to obtain the results.

\section{RESULTS AND DISCUSSIONS}

For this study, SEM images of PVP/GEL nanofibers were taken (with various magnifications) before and after the crosslinking process. Before the crosslinking process, SEM results and histogram curve of electrospun PVP/GEL nanofibers are given in figure 1.

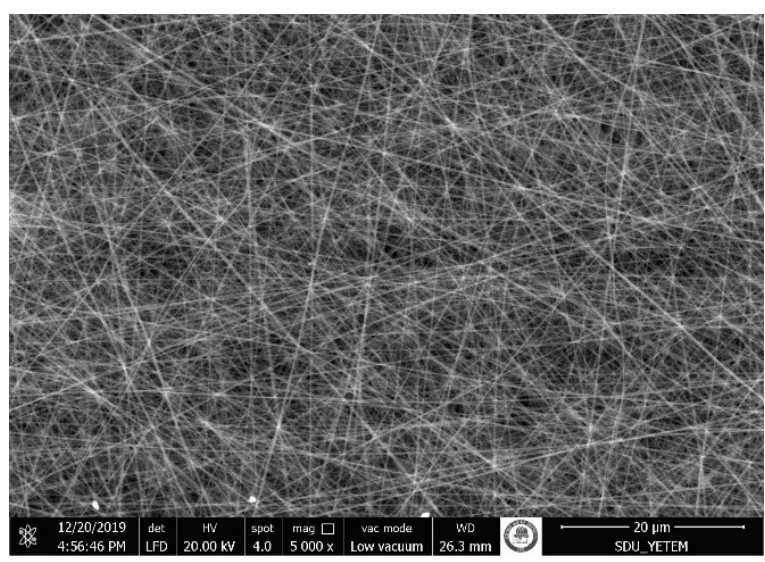

$\boldsymbol{a}$

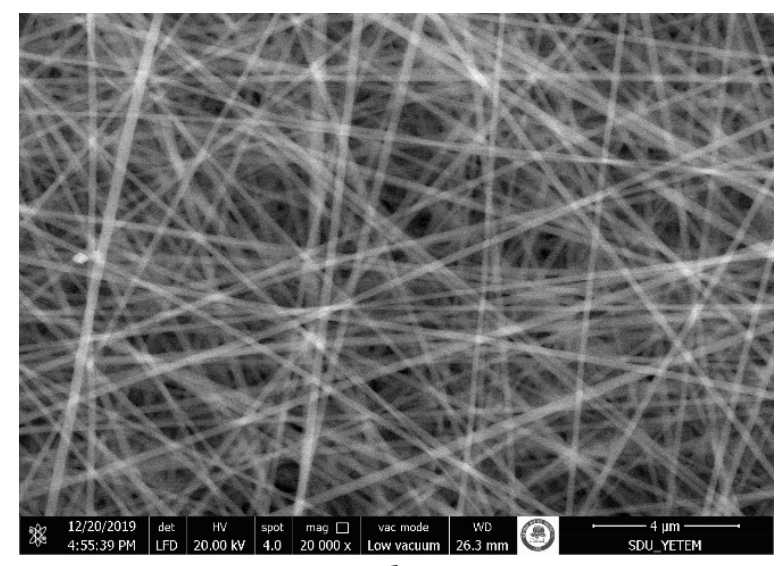

b

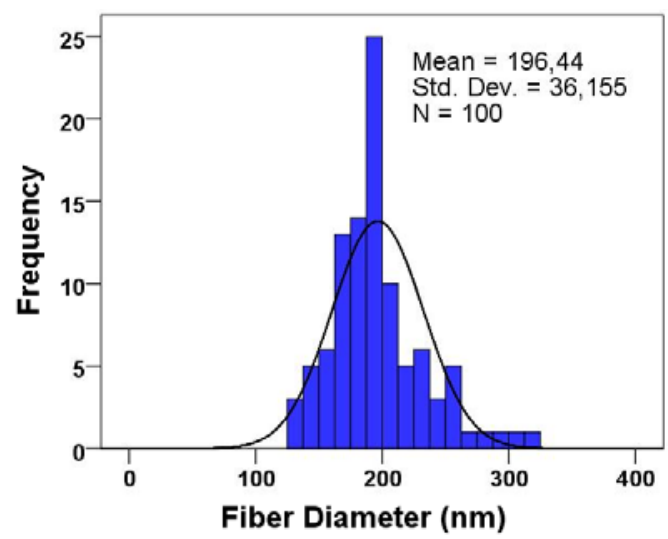

C

Figure 1. SEM images and fiber diameter histogram of PVP/GEL nanofibers before crosslinking

According to figure 1 , it has been seen clearly that nanoweb quality is good and quite smooth and fine nanofibers can be obtained. Furthermore, the average fiber diameter is $196 \mathrm{~nm}$, there is a unimodal histogram curve, and the fiber diameter distribution is uniform.

SEM images of crosslinked PVP/GEL nanofibers at optimum process parameters are given in table 1. SEM images showed that all crosslinked nanofibrous surfaces turned into membranous structures as expected result. It is seen that the fibrous structure is more preserved as the processing time and temperature increase. 
Table 1. SEM images of PVP/GEL nanofibers after crosslinking and swelling tests at various conditions.

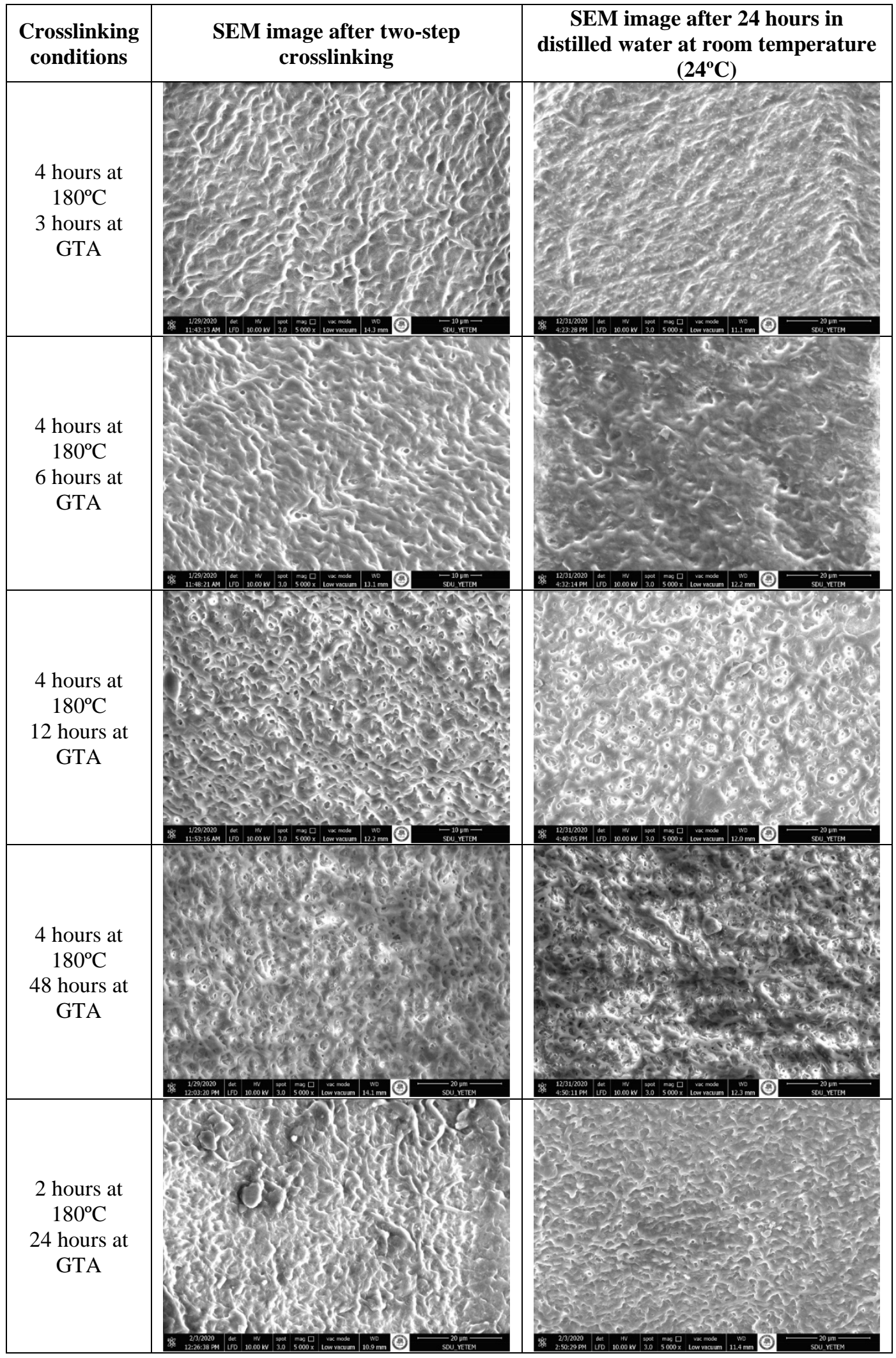




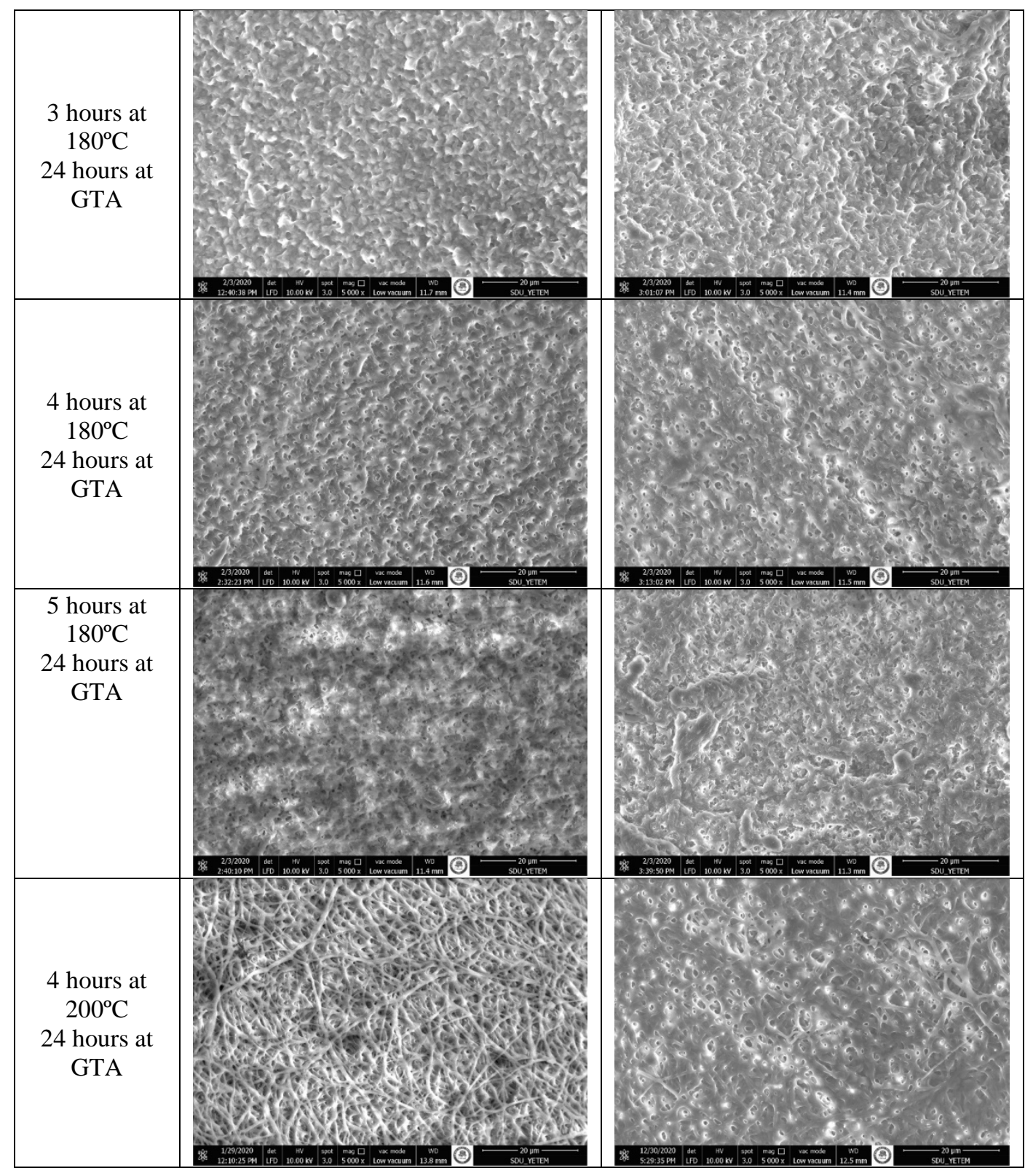

After swelling tests, SD and WL values of PVP/GEL nanofibers were calculated under various crosslinking conditions using equations 1 and 2 which were explained in the methods part. The results are given in table 2 .

Table 2. SD and WL values of PVP/GEL nanofibers after swelling test

\begin{tabular}{|c|c|c|}
\hline Crosslinking conditions & $\begin{array}{c}\text { SD } \\
\text { (\%) }\end{array}$ & $\begin{array}{c}\text { WL } \\
\text { (\%) }\end{array}$ \\
\hline $\begin{array}{c}\text { 4 hours at } 180^{\circ} \mathrm{C} \\
\text { 3 hours at GTA }\end{array}$ & 1130 & 27.71 \\
\hline $\begin{array}{c}\text { 4 hours at } 180^{\circ} \mathrm{C} \\
\text { 6 hours at GTA }\end{array}$ & 862.29 & 23.75 \\
\hline $\begin{array}{l}\text { 4 hours at } 180^{\circ} \mathrm{C} \\
12 \text { hours at GTA }\end{array}$ & 356.60 & 15.87 \\
\hline $\begin{array}{c}4 \text { hours at } 180^{\circ} \mathrm{C} \\
24 \text { hours at } \mathrm{GTA}\end{array}$ & 271.62 & 11.90 \\
\hline $\begin{array}{l}4 \text { hours at } 180^{\circ} \mathrm{C} \\
48 \text { hours at } \mathrm{GTA}\end{array}$ & 281.96 & 12.85 \\
\hline
\end{tabular}




\begin{tabular}{|l|c|c|}
\hline $\begin{array}{l}2 \text { hours at } 180^{\circ} \mathrm{C} \\
24 \text { hours at GTA }\end{array}$ & 268.86 & 23.39 \\
\hline $\begin{array}{l}3 \text { hours at } 180^{\circ} \mathrm{C} \\
24 \text { hours at GTA }\end{array}$ & 214.49 & 20.28 \\
\hline $\begin{array}{l}4 \text { hours at } 180^{\circ} \mathrm{C} \\
24 \text { hours at GTA }\end{array}$ & 224 & 9.63 \\
\hline $\begin{array}{l}200^{\circ} \mathrm{C}^{\prime} \text { de } 4 \text { saat } \\
\text { GTA'da } 24 \text { saat }\end{array}$ & 282.83 & 18.78 \\
\hline
\end{tabular}

Crosslinking results show that crosslinking could not be achieved at $150^{\circ} \mathrm{C}$. Although experiments were carried out at different times, it was seen that the temperature was insufficient. As the holding time at $180^{\circ} \mathrm{C}$ decreases, it is clearly seen that the surface passes through from the fiber form to the membrane form. It was observed that the nanofiber surface almost completely preserved the fiber form from the SEM images taken after crosslinking at $200^{\circ} \mathrm{C}$, but this fiber form disappeared in SEM pictures captured after the swelling test. It was decided that the temperature of $200^{\circ} \mathrm{C}$ was not suitable for the crosslinking process for PVP polymer, considering both the high temperature and the values of SD and WL. For this reason, in the first stage of the study, it was decided that the process time of 4 hours at $180^{\circ} \mathrm{C}$ was optimum.

Similarly, in the second stage of the study, it was observed that the nanofibrous surfaces tried to protect the fiber form as the processing time increased in the GTA application. However, because the SD and WL values were higher, there was no significant difference between SEM images, and the procedure duration was longer, it was determined that the optimum time would be 24 hours rather than 48 hours.

FT-IR spectroscopy confirmed the presence of PVP and GEL polymers in the chemical structures of the nanofibers (figure 2).

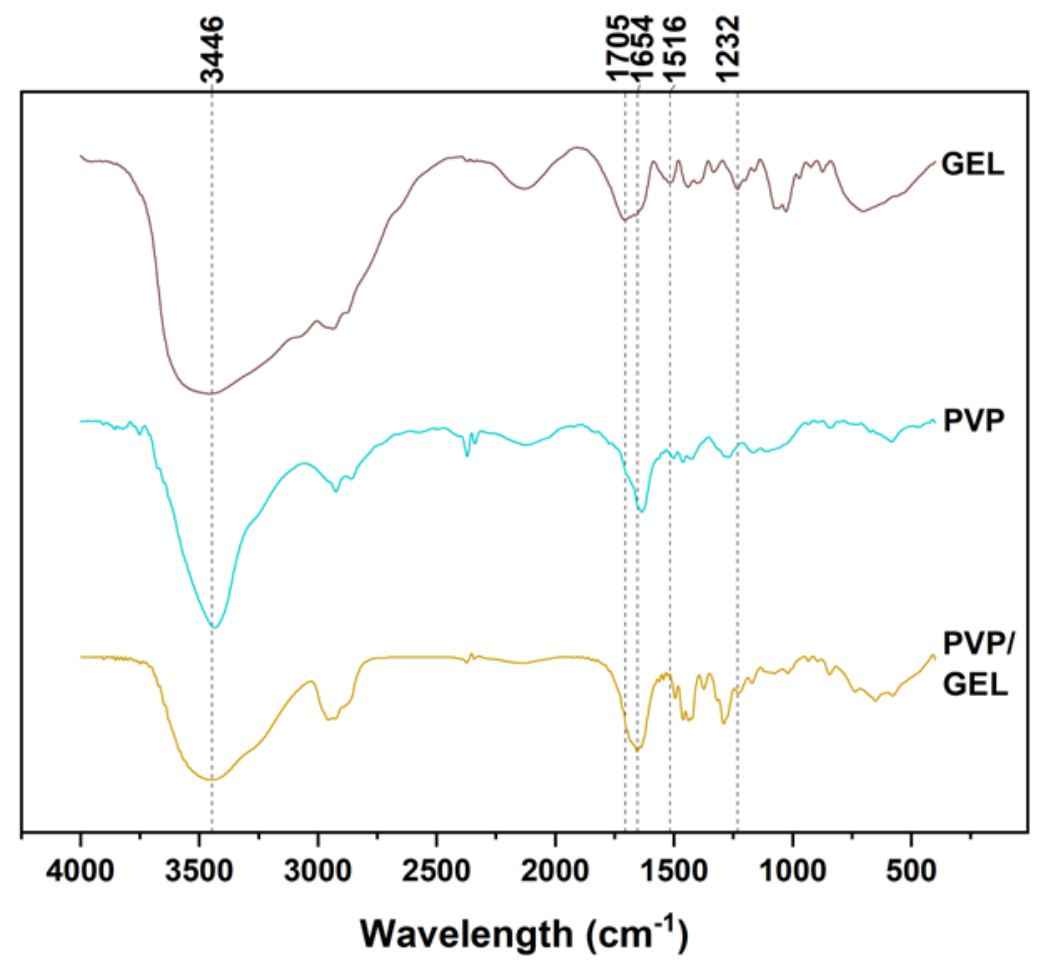

Figure 2. FT-IR spectra of PVP and GEL polymers and PVP/GEL nanofibers 
There is an $\mathrm{OH}$ stretching intensive peak that was attributed to the presence of water at $3434 \mathrm{~cm}^{-1}$. This intensive peak appeared crosslinked PVP/GEL nanofibers at $3446 \mathrm{~cm}^{-1}$. There is another peak that occurred related to $\mathrm{C}=\mathrm{O}$ at $1654 \mathrm{~cm}^{-1}$ in the spectra of PVP. This peak arises from the spectra of PVP/GEL nanofibers at $1659 \mathrm{~cm}^{-1}$. Similarly, there were three major absorption bands in the spectra of gelatin and nanofiber samples: amide $\mathrm{I}(\mathrm{C}=\mathrm{O}$ stretch), amide II ( $\mathrm{N}-\mathrm{H}$ bend and $\mathrm{C}-\mathrm{H}$ stretch), and amide III (C-N stretch plus $\mathrm{N}-\mathrm{H}$ inphase bending). In the spectra of gelatin, amide I, amide II, and amide III peaks were shown at around $1705 \mathrm{~cm}^{-1}, 1516 \mathrm{~cm}^{-1}$, and $1232 \mathrm{~cm}^{-1}$, respectively. These characteristic peaks were determined in the spectra of the nanofibers [8].

\section{CONCLUSIONS}

This study achieved optimization and characterization of crosslinked PVP/GEL nanofibers. According to the results, 4 hours at $180^{\circ} \mathrm{C}$ for PVP and 24 hours at GTA vapors for GEL were selected as the optimum. Crosslinking of PVP/GEL nanofibers in two steps could be carried out successfully. At the end of this study, these two polymers can be used in many application areas involving aqueous media. Thus, it is thought that the crosslinking of these two polymers commonly used in biomedical applications in a nanoweb will contribute significantly to the literature.

\section{ACKNOWLEDGEMENTS}

The authors would like to express appreciation for the financial support of the Süleyman Demirel University Scientific Researches Project Unit [Project Number $=$ FDK2019-6761] and The Scientific and Technological Research Council of Turkey [Project Number $=119 \mathrm{M} 880]$.

\section{REFERENCES}

[1] Dhandayuthapani, B., Krishnan, U.M., Sethuraman S., Fabrication and characterization of chitosan-gelatin blend nanofibers for skin tissue engineering, In: J. Biomed. Mater. Res. - B Appl. Biomater., 2010, 94, 1, 264-272, https://doi.org/10.1002/jbm.b.31651

[2] Wang, L., Chang, M. W., Ahmad, Z., et al., Mass and controlled fabrication of aligned PVP fibers for matrix type antibiotic drug delivery systems, In: Chem. Eng. J., 2017, 307, 661-669, http://dx.doi.org/10.1016/j.cej.2016.08.135

[3] Ki, C.S., Baek, D.H., Gang, K.D., et al., Characterization of gelatin nanofiber prepared from gelatin-formic acid solution, In: Polymer, 2005, 46, 14, 5094-5102, https://doi.org/10.1016/j.polymer.2005.04.040

[4] Rosa, R.M., Silva, J.C., Sanches, I.S., et al., Simultaneous photo-induced cross-linking and silver nanoparticle formation in a PVP electrospun wound dressing, In: Mater. Lett., 2017, 207, 145-148, https://doi.org/10.1016/j.matlet.2017.07.046

[5] Lubasova, D., Niu, H., Zhao, X., et al., Hydrogel properties of electrospun polyvinylpyrrolidone and polyvinylpyrrolidone/poly (acrylic acid) blend nanofibers, In: RSC Adv., 2015, 5, 67, 5448154487, https://doi.org/10.1039/C5RA07514A

[6] Laha, A., Sharma, C.S., Majumdar, S., Sustained drug release from multi-layered sequentially crosslinked electrospun gelatin nanofiber mesh, In: Mater. Sci. Eng. C, 2017, 76, 782-786

[7] Zhang, Y.Z., Venugopal, J., Huang, Z.M., et al., Crosslinking of the electrospun gelatin nanofibers, In: Polymer, 2006, 47, 8, 2911-2917

[8] Cengiz Çallığlu, F., Kesici Güler, H., Sesli Çetin, E., Emulsion electrospinning of bicomponent poly (vinyl pyrrolidone)/gelatin nanofibers with thyme essential oil, In: Materials Research Express, 2019, 6, 12, 125013, https://doi.org/10.1088/2053-1591/ab5387 